\section{Gentle Persuasion}

\section{from a Correspondent}

Is an effort to disabuse $\mathrm{PhD}$ students of the notion that academic research is the only respectable outcome of a scientific education, the Science Research Council and the Careers Research and Advisory Centre have just organized an eight day summer school at University College, Oxford, in association with the London Business School. The aim was to introduce postgraduate students to the many different types of industrial and administrative problems, and to show that these are stimulating and as worthy of attention as more academic work. The presence of $50 \mathrm{PhDs}$ from industry gave the postgraduate students the opportunity for discussing informally aspects of careers in industry and administration.

Extensive use was made of case studies of actual companies and group exercise methods involving the full participation of the students. The contents of the course were generally completely new to the postgraduate students, and included topics as diverse as operational research, the financial problems of capital project appraisals and systematic management dedelopment. Aspects of business not usually looked on favourably by postgraduates-marketing, for example -were made to seem interesting. Demonstrations of modern techniques such as operational research and systems analysis, which help the manager in making decisions, won an attentive audience-although one which frequently asked to what extent these scientific methods are actually applied in British industry.

The highlight of the week for the majority of the students was a business game-an attempt to simulate a dynamic business situation for a number of competing teams made up of students representing the senior executives of the companies concerned. As well as giving the participants a chance to test their management acumen, the game provided an understanding of the workings of a company and an appreciation of the conflicts which can arise in the board room.

The course was not in any sense a careers convention and there was no recruiting by specific firms. It succeeded in providing a valuable insight into the mechanisms of business and a glimpse of the administrative skills required of a successful manager. Many of the PhD students remained sceptical, however. Doubts were expressed whether anyone entering a large company through a research and development department, as the majority of those present would do, could ever rise to a senior executive position. Beliefs like this, which have developed over several years in an academic climate, cannot be altered so easily, and a first impression of the course is that it may have hardened attitudes rather than have changed them.

The organizers are wisely being cautious in judging the success of their venture. A questionnaire designed to discover attitudes to industry was filled in by all the participants before and after the summer school and will be completed again in several months, when the effects of the course will be more readily discernible. Until the results are known it will be too early to draw any definite conclusions.

\section{Informed Chemists}

Alx five hundred chemistry $\mathrm{PhD}$ students in their final year at British universities who are being supported by an SRC grant are to take part in an experiment with the Chemical Society's Research Unit in Information Dissemination and Retrieval at the University of Nottingham. The unit will provide the chemists with relevant references from the literature, which are selected by computer so that the value of the service can be assessed and changes made if necessary. Six liaison officers, who are themselves chemists, from the Chelsea College of Science and Technology, and the universities of Edinburgh, Oxford, London, Warwick and York, have been appointed to provide a link between the students and the unit.

The liaison officers will meet the heads of the university chemistry departments in their areas next month to explain the scheme. They will then meet the students and, using the references the students have found useful, will work out a reference "profile" for each student to be fed into the unit's computer. The computer will then give the student a list of up to date references relevant to his line of research every two weeks. The liaison officers will meet the students six or seven times during the year to make sure that they are getting a suitable service. It is hoped that the service will give the students a good introduction to the use of mechanized information services and that the experience gained will be spread widely when the students take up employment in government, industrial and university laboratories.

The Office for Scientific and Technical Information, which is organizing this project, is also giving a grant of $£ 56,000$ to the Chemical Society's Unit to extend its programme of work for the next two years. The research unit, which gave a demonstration at the Chemical Society's autumn meeting in Durham this week, is financed jointly by the Chemical Society and the Office of Scientific and Technical Information. During the past nine months it has regularly provided about 250 people in various government, industrial and university research laboratories with lists of titles of research papers. The titles have been selected by a computer comparing a machine readable statement of their research interests with magnetic tape versions of two Chemical Abstracts Service publications, Chemical Titles and Chemical Biological Activities.

\section{Dispensing with Meteorologists}

THE Proceedings of the World Meteorological Organization's Conference on Automatic Weather Stations, held in Geneva a year ago, have now been published. In his opening statement, Mr D. A. Davies, secretary-general of WMO, said that studies had shown that while observational satellites undoubtedly marked a turning point in meteorology, the full benefits would only be reaped if a complementary system for observing the atmosphere from the Earth's surface itself was available. The problems of establishing and maintaining an adequate network of observing stations, especially in the uninhabited regions, meant that automatic weather stations would become increasingly important.

In a report on US Weather Bureau Automatic Stations, Mr A. N. Hill said that the US Weather Bureau had a large number of "co-operative observers" who took daily readings, but because of increased personal mobility they were becoming reluctant to give daily readings and for this reason would need to be replaced. A simple data logger was required and 